\title{
Analysis on the Old City Reconstruction and City Style Shaping of Anyang City
}

\author{
Chenyang Shen, Jiahua Li \\ School of Civil Engineering and Architecture, Southwest University of Science and Technology, Mianyang, China \\ Email: mirshen@126.com
}

How to cite this paper: Shen, C. Y., \& Li, J. H. (2021). Analysis on the Old City Reconstruction and City Style Shaping of Anyang City. Current Urban Studies, 9, 392-402. https://doi.org/10.4236/cus.2021.93024

Received: July 9, 2021

Accepted: August 3, 2021

Published: August 6, 2021

Copyright $\odot 2021$ by author(s) and Scientific Research Publishing Inc. This work is licensed under the Creative Commons Attribution International License (CC BY 4.0).

http://creativecommons.org/licenses/by/4.0/

\begin{abstract}
Anyang City is a prefecture-level city under the jurisdiction of Henan Province. It is located in the northernmost part of Henan Province. It is one of my country's eight ancient capitals and a national historical and cultural city. The current Anyang Old City retains the ancient northern plain architecture and residential groups based on the architectural styles of Ming and Qing Dynasties. In the modern economic construction today, the urban style in the old city of Anyang is dilapidated, the old city functions are chaotic, the living environment of residents is low, and the old city features and the space are in urgent need of transformation. This article starts with combing the status quo of the ancient city of Anyang, analyzes the existing problems of the protection of the ancient city of Anyang, and explores the path of combining the traditional architectural features of the old city with the new architectural features, highlighting the characteristics of the ancient city, and creating an urban business card belonging to Anyang.
\end{abstract}

\section{Keywords}

Anyang Old City, Transformation, Style Shaping, Cultural Inheritance

\section{Introduction}

Anyang has a long history of urban construction. At present, the old city has preserved a large number of traditional buildings dominated by Ming and Qing dwellings. After continuous renewal and development of the city, in 2000, the development of the old city's muscles was severely affected by the development of Wenfeng Middle Road in the middle of the old city. At the same time, buildings full of modernization began to flood into the old city quickly. Some traditional streets and buildings with high preservation value were demolished and replaced by some large-scale constructions that were incompatible with the block 
texture on the grounds of tourism development. Architecture has brought a fatal blow to the function and style of the old city that has already been devastated. Our previous governments lacked foresight, because they built new cities, demolished the Ming and Qing buildings in the ancient city, and destroyed the architectural heritage. This is the debt owed to the protection of the ancient city. Today, it is here to pay the debt. It is hard to say whether it can be paid off (Yisan Ruan, 2003). Professor Ruan Yisan criticized the destruction of Anyang's old city by name in "The Documentary of the Castle", expressing his anxiety, indignation and helplessness over the destruction of the ancient city of Anyang. The existing old city of Anyang has chaotic functions, aging buildings, and dilapidated traditional features. How to transform and shape the old city of Anyang has become an urgent problem in Anyang.

\section{Overview of the Old City of Anyang}

\section{Introduction to the Location of the Old Town of Anyang}

Anyang City is located in the northernmost part of Henan Province, at the intersection of Shanxi, Hebei and Henan provinces. As one of the eight ancient capitals, Anyang has tangible or intangible historical and cultural resources including Oracle, Zhouyi, and Yin Ruins. In 1986, it was identified as the second batch of national historical and cultural cities. The history of Anyang's city construction may originate in the Shang Dynasty. By the end of the Qing Dynasty, there were more than 90 streets in the city. In the existing old city, except for the newly opened Wenfeng Middle Road, the remaining main roads are East, West, South, and North Avenues. There are 18 branch streets in the South and North Avenues, which are called Eighteen Arhat Streets. The streets and alleys crisscross, with the reputation of Jiufu, Eighteen Alleys, and Seventy-two Alleys (Ping Zhang, 1997). The profound sense of history also laid a good foundation for the shaping of Anyang's urban style.

\section{The Urrent Situation of Anyang Old City}

\subsection{Building Exterior Damage}

Except for the more representative buildings in the old city of Anyang, such as Tianning Temple, Chenghuang Temple, Gaoge Temple and other cultural preservation buildings, the remaining buildings with a sense of age basically have natural weathering and man-made damage. The appearance of the old city buildings is dilapidated and many traditional buildings are in a vacant state. Due to disrepair for a long time, the problem of building collapse is more prominent. This is also the main problem existing in the ancient city.

\subsection{No Characteristics of Shops in Urban Areas}

The opening of Wenfeng Avenue in the old city has brought economic benefits and tourism benefits. In order to create a large-scale commercial complex, the 
architectural style has not hesitated to construct traditional ancient buildings with a concrete frame structure, which has caused serious distortion. At the same time, it has created a commercial without any regional characteristics, the replicated snack street, shopping city, and the same appearance will cause the aesthetic fatigue of tourists, and at the same time reduce the pedestrian vitality of the block, without commercial competitiveness. At the same time, the living quarters of the residents in the old district have long been dilapidated, and the quality of the store environment is poor. The problem of street renovation is urgent.

\subsection{Aging Infrastructure and Low Level of Urban Landscape Water System}

Since the development of Anyang New District to the east, the construction of the original infrastructure in the old city has stopped. These infrastructures are gradually aging. The current basic problems such as chaotic power lines and inconvenient drainage are more serious. The residents themselves follow their actual lives. The need to change the electric wires privately also poses safety risks. At the same time, the lack of infrastructure has also caused the low quality of the original pond water system in the urban area and the low level of the living environment in the old city (Figure 1).

\subsection{Block Texture Destruction and Road Congestion}

Due to the influence of human life in the old city, the occupation of the streets in the old city blocks is more serious, and the phenomenon of private establishment of shops is common, which makes the traffic roads in the not spacious old city become more congested, and the internal branch roads in the old city are congested (Figure 2).

\section{Case Reference}

\subsection{Liyang Old Street, Anhui}

Liyang Old Street is located in Liyang Town, Tunxi District, Huangshan City, Anhui Province. It has a rich history and is a distinctive representative of Huizhou culture (Figure 3). Liyang Old Street currently extends from the West Town Bridge in the east to the southwest, divided into Upper Liyang and Lower Liyang, with a total length of more than 1200 meters. It has the typical characteristics of "eight half mountains, half water, half farmland and manor" in Huizhou area (Juanbiao Zou \& Wu Qiang, 2010).

The renewal of Liyang Old Street still continues the planning of the "three steps" approach, using texture transformation, architectural design, and landscape construction, and the transformation is mainly to reshape the charm of Huizhou. The old street adopts elements such as bluestone slabs, leaky windows, gates, brick carvings, horse head walls and other elements, still showing the traditional cultural heritage. In the single-plan reconstruction of traditional buildings, the basic 


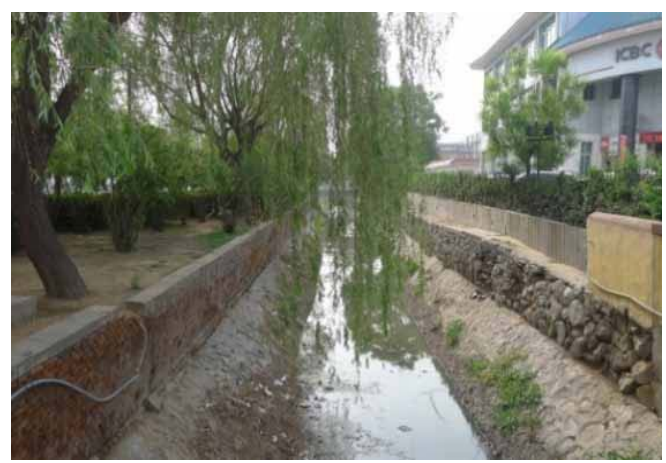

Figure 1. Low water system landscape (Source: Internet search and collation).

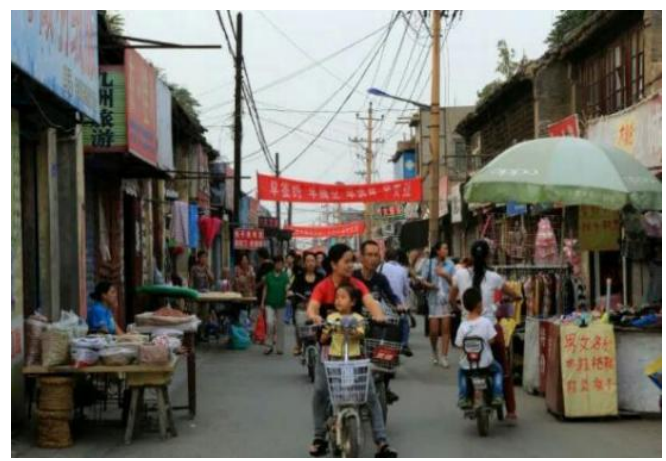

Figure 2. Stores occupying roads cause street congestion (Image source: Internet search and collation).
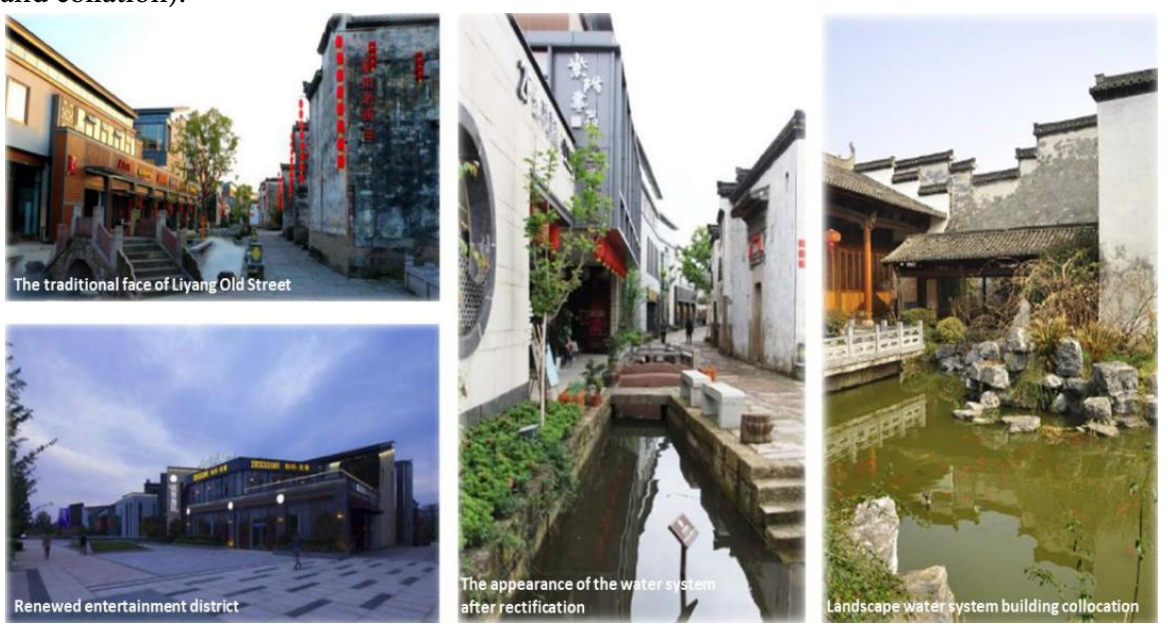

Figure 3. The status quo of Liyang Old Street after the renovation (photo source: after the network search).

construction methods of "famous patios" and "depth sequences" inside traditional Hui style houses are still used to transform appropriate functions according to actual usage requirements. Furthermore, for the newly-renovated buildings, the "white wall, blue tile, horse head wall" and Huizhou style are the main ones. According to the different functions of the block, the traditional style and the modern European block style are combined. Today, the design is rapidly modernized, and the traditional Huizhou style is issued. 


\subsection{Summary}

The renovation of Liyang Old Street shows a classic case of the renovation of old districts with regional characteristics. Today, affected by the architectural culture from outside the region, how to extract traditional regional elements, retain the traditional style, and inject new vitality into the old district. The transformation became an example of the combination of tradition and modernity. Selecting this case can also be used to reflect the small ones. For the old districts with regional and cultural characteristics, a similar model can also be adopted. To improve the old city's functional aging and dilapidated features, replace and rectify the functions of the buildings in a targeted manner, combine traditional culture with modern culture, extract the architectural features of the old city, inject new cultural vitality, and shape the characteristics of the city.

\section{Reconstruction and Style Shaping of Anyang Old City}

The reconstruction and style shaping of the old city of Anyang need to be built in accordance with the original historical building remains morphological characteristics of the historic district to ensure the inheritance of the cultural connotation of the historic district (Lian Wu \& Dan Shen, 2007). Combining with the thinking of the case transformation of Liyang Old Street and the reading of related documents, the following measures are summarized for the transformation and style shaping of Anyang:

\subsection{Rectify Old City Buildings and Shape City Style}

\subsubsection{Classification and Renovation of Buildings}

The current buildings in the old city of Anyang vary greatly according to the age, and the renovation measures are also very different. According to the construction age, it can be roughly divided into three types: buildings before 1949, buildings from 1949 to 1978, and buildings from 1978 to the present, and different measures have been taken to transform them (Table 1).

\subsubsection{Extract Architectural Elements and Shape Architectural Style}

For the shaping of the style and appearance of the old city of Anyang, based on the current situation that the pattern of the ancient city has been destroyed by Wenfeng Road, the modernization of the old city's architecture has been infiltrated seriously and targeted, and the traditional Ming and Qing architectural styles can be combined with modern architectural forms to extract the old city. The architectural elements and symbols of Ming and Qing dynasties left in China are combined with modern construction to create a traditional Ming and Qing quaint city style with traditional style as the main feature and modern construction style as a supplement.

With regard to the extraction of elements from the old city, the traditional buildings in the old city of Anyang, except for the Tianning Temple and other symbolic buildings, most of the remaining practical buildings are traditional Chinese 
Table 1. Building classification renovation measures.

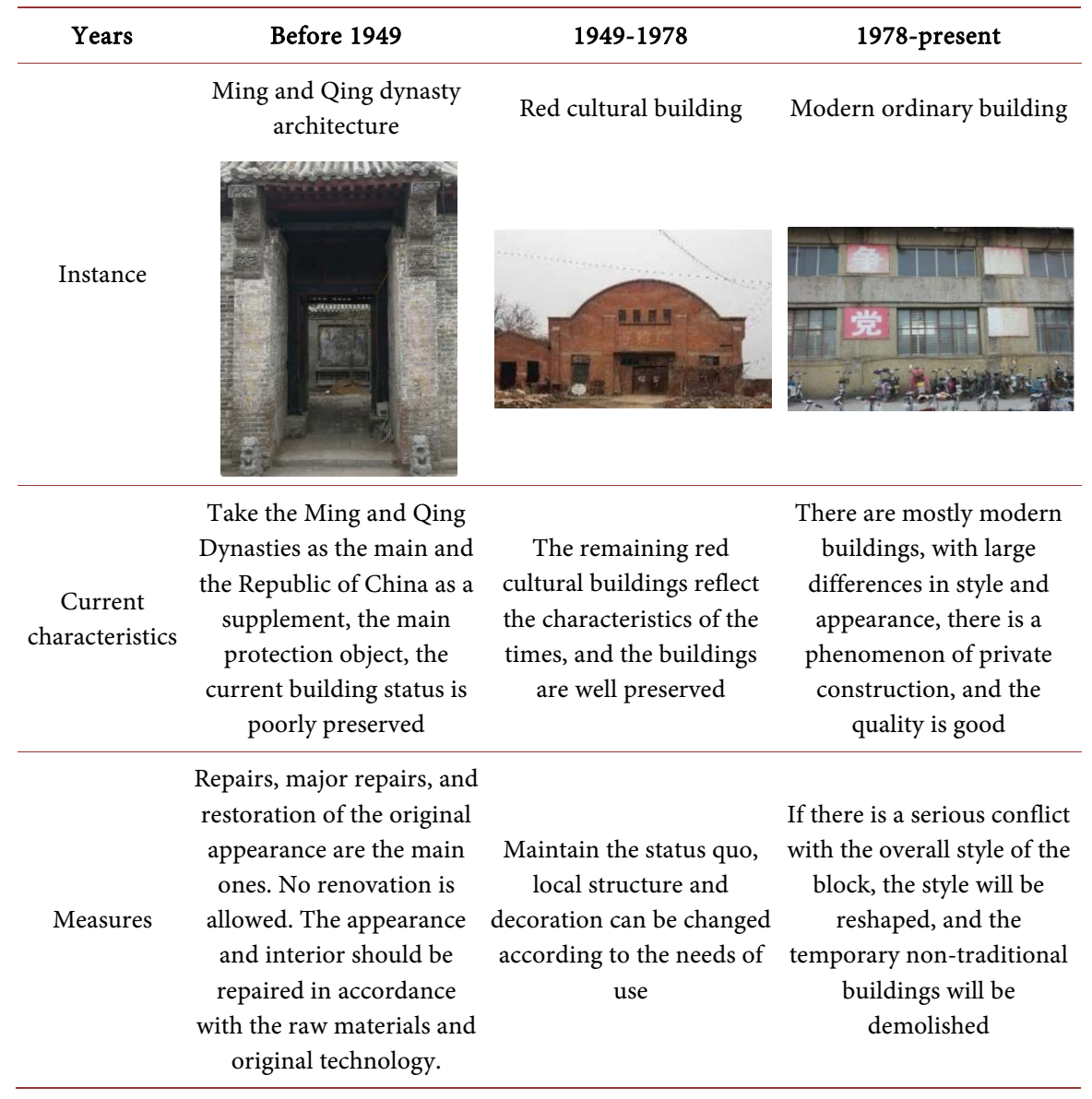

bench-beam architecture frames. In terms of architectural style, most of them are traditional shops with wooden frames and residential buildings mixed with bricks and woods. The external blue brick walls and gray tiles cover the building visually, giving people a sense of historical heaviness; in architecture In terms of layout, most of the multi-entry architectural courtyards are adopted, with three- or fourentry courtyard layout mode as the main; on the building facade, the building bays along the street are mainly two-bay or three-bay, and the number of floors is one floor. Or the second floor is the main; in terms of architectural color, the roof and walls are mainly gray-cyan cool colors, and only the decoration components at the door, screen wall and other details will have warm colors. In the architectural details, rich and diverse components such as wooden doors, windows, hanging fish, and brick carvings are displayed, reflecting the distinctive regional cultural characteristics (Table 2).

\subsection{Create a Regional Functional Zone}

For the creation of regional functional areas, it is not to create a snack street that can be seen everywhere and buy the same product everywhere, but to create a distinctive regional cultural city, including shops, restaurants, and residences. 
Table 2. Anyang traditional old city elements.

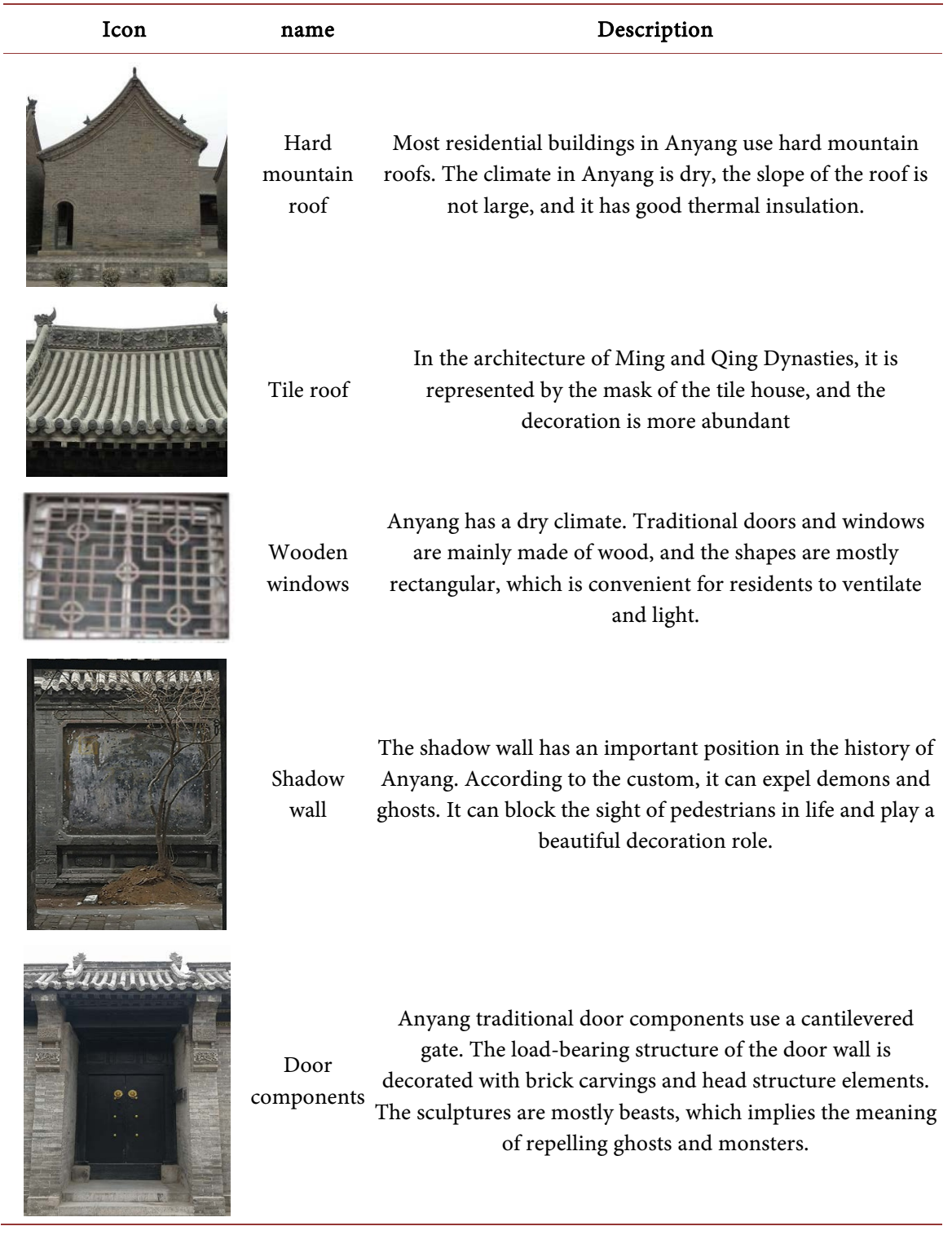

For the transformation of blocks, traditional Anyang cultural elements can be used to create characteristic cultural blocks, which can inspire architectural, cultural and creative shops, restaurants, residences and other functions. This not only improves the actual living environment of local residents, but also enhances the competitiveness of Anyang's tourism culture (Table 3).

\subsection{Improve Infrastructure and Create a Landscape Environment}

The improvement of the landscape infrastructure in the old city of Anyang should take into account the impact on the surrounding traditional buildings, while balancing the needs of tourists and the living needs of the residents of the old city. For the transformation of infrastructure, a pipeline system can be established based on the original texture of streets and lanes to solve the problem of residents' basic 
Table 3. Replacement table of building functions in old districts.

\begin{tabular}{|c|c|c|}
\hline Category & Cultural Features & Description \\
\hline $\begin{array}{l}\text { Cultural and } \\
\text { Creative } \\
\text { Store }\end{array}$ & $\begin{array}{l}\text { Yin Ruins, Oracle Bone } \\
\text { Inscriptions, Eight } \\
\text { Diagrams Culture of } \\
\text { Zhouyi, Si Mu Wu Ding } \\
\text { Bronze }\end{array}$ & $\begin{array}{c}\text { The store combines the local characteristics of Anyang to } \\
\text { create cultural and creative products, allowing people to } \\
\text { buy commemorative goods such as Anyang's regional } \\
\text { iconic imitation oracle bone pieces, Zhouyi Bagua } \\
\text { decorations, etc. }\end{array}$ \\
\hline food & $\begin{array}{l}\text { Flat vermicelli, Anyang skin } \\
\text { dregs, Laomiao beef, } \\
\text { Daokou roast chicken, fried } \\
\text { blood cake }\end{array}$ & $\begin{array}{l}\text { Anyang's food culture is also representative, which can } \\
\text { create an Anyang characteristic food district }\end{array}$ \\
\hline live & $\begin{array}{l}\text { Ming and Qing Dynasties } \\
\text { Residential Buildings }\end{array}$ & $\begin{array}{l}\text { For traditional houses that are dilapidated and vacant, } \\
\text { they can be renovated and transformed into facilities } \\
\text { such as homestays, and vacant buildings can be reused }\end{array}$ \\
\hline
\end{tabular}

living facilities. Try to combine pipeline systems such as lines with underground drainage facilities. Through the establishment of underground pipe networks, solve the problem of line clutter on the ground and free up ground space. At the same time, combine the Yinxu element symbols to arrange public facilities such as toilets and seats.

In view of the current situation, the old city can be combined with the moat and waterfront ponds in the landscape transformation, and the old city can be divided into a combination of point, line and surface greening to connect the old city greening in series. Although Anyang is located in the north, the water system network inside and outside the city is rich. Whether it is Huanshui in the outskirts of the city or the branch of the moat that passes through the city, enough water systems are given to the old city. For the landscape reconstruction of the old city, the ponds left by these branches can be used as the main body to create a landscape combining greenery and water system (Figure 4). At present, the most successful one is the transformation of the old city located in the triangle lake park in the northwest corner. The original pit bottom of the triangle lake was used to create the triangle lake area, dot (triangle lake), line (green corridor around the lake), surface (triangle lake). In the landscape of the overall green area of the lake, Sanjiao Lake Park has also become one of the prominent parks in Anyang City.

\subsection{Improving Travel Modes and Alleviating Traffic Pressure}

In terms of traffic management, the traffic scale of Anyang Old City is restricted by the street texture of the ancient city, and there is not much room for expansion in scale. Therefore, for some narrow streets and lanes, motor vehicles can be prohibited; at the same time, it can be improved by improving travel. Start with the method, increase the distribution of shared trams or bicycles, so as to relieve the pressure of vehicle traffic within the limited scale texture of the ancient city; in terms of vehicle travel restrictions, the strategy of "restricted traffic at peak and night traffic" can be adopted. Vehicles are limited in flow between 8 o'clock. 


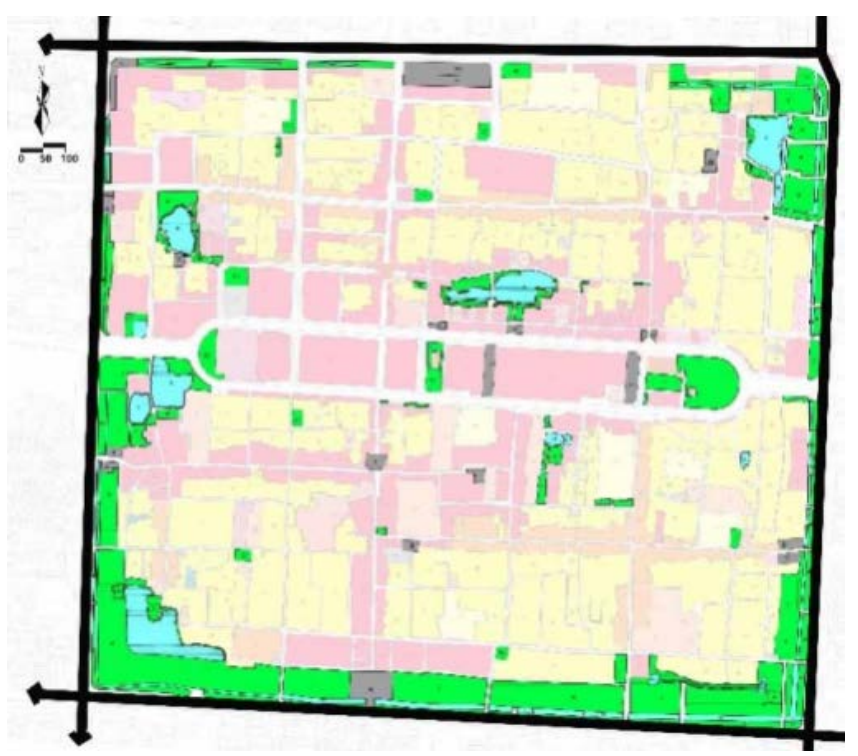

Figure 4. Layout of the current landscape of Anyang City (picture source: Anyang Urban Construction History).

For parking, it is possible to divide the cell group. In the planning unit, the area reserved for some demolished buildings is converted into a parking building with the characteristics of the ancient city. By increasing the three-dimensional parking space, the problem of parking in the old city can be solved. Difficult question.

\subsection{Participation of the Government and Residents}

The transformation of the old city is inseparable from the rigid support and guidance of policies. At the same time, it also requires the active participation of residents, so that the transformation of the old city of Anyang and the shaping of its style can be realized.

As for the government at the planning level, it can formulate a "top-down" policy system and use rigid means to plan and shape the style of the old city. In emerging buildings, the architectural styles that conform to Anyang's regional culture should be the mainstay, and the appearance of exotic buildings should be avoided.

As the people, it can also play a "bottom-up" role. This also requires the government to actively communicate, establish the awareness of the ancient city style in the daily life of the old city residents, protect the ancient building culture from life, refuse to build privately, and continue the traditional cultural style awareness in the housing appearance transformation. Keep the memory of the ancient city and find the sense of belonging of Gu Yun's hometown.

\section{Conclusions and Outlook}

Anyang's old city reconstruction and urban style shaping methods are based on the status quo, combining traditional architectural elements with modern con- 
struction, while continuing regional customs and culture, while adding new vitality to the old city. Therefore, the conclusions of this article are as follows:

First, the appearance of the original buildings in the old city of Anyang is dilapidated, and the buildings should be classified and renovated, and different types of architectural elements should be extracted to shape the architectural style of the old city.

Second, create a district with regional characteristics in the old city of Anyang, and create a comprehensive cultural district including shops, restaurants, and residences by digging out local characteristic culture to activate the vitality of urban districts.

Third, upgrade the infrastructure, improve the landscape environment, and upgrade the infrastructure on the basis of the original water system and street space to enrich the water system and green landscape.

Fourth, improve residents' travel modes, relieve traffic pressure, and improve residents' traffic travel pressure by implementing different sections and different modes of travel.

As a fourth-tier city, Anyang City does not have strong economic power to support the rapid transformation of the old city. The transformation and style shaping of the old city must be a long-term process, which also requires the joint participation of the government and local residents. Today, when urban development is affected by foreign cultures, creating an architectural culture with regional characteristics in Anyang, combining tradition with modernity, and inheriting the cultural characteristics of the ancient city is the basis for Anyang's future city business card, whether it is from the planning and construction of the old city, or the architectural culture. In terms of inheritance, the regional characteristics of traditional Ming and Qing architecture cannot be lost. After all, there is only one ancient city in Anyang.

\section{Acknowledgements}

First of all, I would like to thank classmate Ruiqing Ding for helping me during the field investigation, and for the field investigation together with me. Second, I would like to thank Mr. Li Jiahua for his guidance on the structure and content of this paper.

\section{Conflicts of Interest}

The authors declare no conflicts of interest regarding the publication of this paper.

\section{References}

Ruan, Y. S. (2003). Records of the City Moat. China Construction Industry Press.

Wu, L., \& Shen, D. (2007). Research on the Organic Renewal and Vigor Rejuvenation of Historic Districts-A Case Study of the Conservation Planning of Minzhushang Street Historic District in Tongren, Qinghai. Urban Development Research, 14, No. 2, 110-114. 
Zhang, P. (1997). Anyang City Urban Construction History. China Construction Industry Press.

Zou, J. B., \& Qiang, W. (2010). The Construction of Urban Tourism Cultural Image Based on Urban Design-A Case Study of the Urban Design of the Waterfront Area of Fuziling Town in Lu'an City, Anhui Province. Urban Planning, 34, No. 4, 92-96. 